\title{
PRODUTOS NÃO MADEIREIROS: CONCEITUAÇÃO, CLASSIFICAÇÃO, VALORAÇÃO E MERCADOS
}

\author{
Anadalvo J. dos Santos ${ }^{1}$ \\ Elisabeth Hildebrand ${ }^{2}$ \\ Carlos H. P. Pacheco ${ }^{2}$ \\ Paulo de Tarso de L. Pires ${ }^{2}$ \\ Roberto Rochadelli ${ }^{2}$
}

\begin{abstract}
RESUMO
Este artigo apresenta uma revisão bibliográfica sobre produtos não madeireiros visando traçar um panorama sobre os seus principais conceitos, classificação, valoração e mercados. Constata-se a necessidade de análises mais aprofundadas sobre a importância sócio-econômica desse grupo de produtos, criando assim, uma nova linha de pesquisa florestal. Estas analises são fundamentais no caso brasileiro devido a diversidade e extensão do ecossistemas florestais existentes no país.

Palavras chave: produtos não madeireiros, extrativismo, economia florestal
\end{abstract}

\section{NON-WOOD PRODUCTS: CONCEPTS, CLASSIFICATION, ECONOMIC VALUATION AND MARKETS}

\begin{abstract}
This article presents a bibliography review on non wood forest products seeking to have a view about the main concepts, classification, economic valuation and markets. It's necessary to do a deeper analysis about the socioeconomic importance of this group of products in order to create a new forest research area. These analysis are important in Brazil because of the forest ecosystem diversity and extension.

Key-words: Non-wood products; estractivism, economy
\end{abstract}

\section{INTRODUÇÃO}

Ao longo da história as florestas têm sido valorizadas pela variedade de produtos e benefícios que delas provêm, tanto para a subsistência quanto para o comércio, tais como: alimentos, produtos medicinais, especiarias, resinas, gomas, látex, vida selvagem, combustível, e obviamente madeira e outros produtos madeireiros. A literatura é rica em exemplos de comércio internacional feito a partir de produtos florestais.

Entretanto, na maior parte da era moderna o desenvolvimento das perspectivas florestais têm-se limitado aos recursos de apenas um produto: madeira. Essas perspectivas resultam em um uso intensivo dos recursos madeireiros, em detrimento da constante desconsideração do restante do ecossistema florestal. Os habitantes das florestas tem sido particularmente atingidos, pois se por um lado são freqüentemente beneficiados com a extração de madeira, por outro dependem dos outros recursos florestais que são depredados.Mais recentemente, entretanto, acredita-se que essa valorização apenas da produção madeireira, em um contexto macroeconômico, vem sendo gradualmente modificada. Torna-se cada vez mais claro que as florestas proporcionam uma gama enorme de outros produtos e benefícios, muitos dos quais longamente conhecidos e utilizados pelos habitantes locais, e em alguns casos ainda essenciais à sua sobrevivência.

O desafio é a correta quantificação e projeção do valor dos produtos não

\footnotetext{
Ajsantos@floresta.ufpr.br, Doutor, Depto de Economia Rural e Extensão da UFPR, Rua Lothário Meissner - 3400, Curitiba, PR.

2 Doutores pelo Programa de Pós-Graduação em Engenharia Florestal da UFPR.
} 
madeireiros, e dessa forma transformar muitos desses produtos em alternativas comerciais, sociais e ecológicas viáveis, para alguns de subsistência, e para outros de desenvolvimento.

De acordo com Wickens (1991), esse aumento da utilização dos produtos não madeireiros é entendido como um processo que resulta na sua destruição. As culturas e as comunidades movendo-se em direção à economia de mercado fazem como que o uso de subsistência desses produtos tenda a desaparecer. Infelizmente, esse decréscimo normalmente não ocorre em paralelo, ou na mesma proporção, que o acréscimo no manejo e seleção dos produtos não madeireiros, e que faz parte do processo de desenvolvimento. Como conseqüência, o conhecimento tradicional a respeito desses produtos pode se perder. E, normalmente o conhecimento do verdadeiro valor desses produtos para a comunidade e a nação só é compreendido quando os recursos já desapareceram.

Wickens, (1991), acrescenta que outro fator importante é o incremento das pesquisas em relação aos produtos não madeireiros, isto é, sua abundância, distribuição, variação, ecologia, reprodução; métodos tradicionais e novos de propagação, cultivo e uso; identificação do mercado e valor, são essenciais. Estudos de casos mostram como os produtos podem ser usados, a extensão desses usos e como estão mudando. Também é importante identificar os usuários e quais grupos são mais dependentes para a subsistência. O potencial de novos produtos também deveria ser considerado.

A contribuição dos produtos não madeireiros para o setor florestal é significativa para a maior parte dos países e estudos desenvolvidos por Campbell \& Tewari na Índia mostram que estes produtos foram subvalorizados no passado.

As florestas, com os seus produtos representam importantes recursos sócioeconômicos através dos potenciais alimentícios, oportunidades de emprego, turismo e outros produtos, além dos madeireiros.

Entretanto, com o crescimento da população e decréscimo da base desses recursos florestais, esses produtos, geralmente extrativos, encontram-se sob crescente pressão (Unasylva, 1991).

Segundo Campbell \& Tewari (1996), tem crescido o sentimento de que o manejo e desenvolvimento dos recursos não madeireiros são indispensáveis, por várias razões: manejo florestal voltado à produção de produtos não madeireiros pode ser ecologicamente e economicamente sustentável, desde que adequadamente utilizado, ou seja, que as taxas de extração não sejam superiores À produção máxima equilibrada. Comunidades indígenas têm sido envolvidas na utilização destes produtos, sem destruir a base dos recursos. Manejar florestas para a produção de produtos não madeireiros também implica em manter a diversidade biológica de espécies animais e vegetais; produtos não madeireiros são um recurso vital para sobrevivência de uma grande porção dos moradores pobres que vivem dentro ou próximo de florestas, na maior parte dos países tropicais; e além da subsistência e potencial de renda, esses produtos proporcionam segurança alimentar para uma grande parte da população de baixa renda, para o gado e outros animais domésticos, particularmente em épocas de seca e escassez.

Os produtos não madeireiros também representam um dos mais desafiadores grupos de produtos, do ponto de vista de mercado, devido ao seu número, versatilidade, variação de uso final, diferenças da base de produtores e riqueza de recursos. Um exemplo são os 3000 óleos essenciais conhecidos, dos quais aproximadamente 300 possuem importância comercial (Lintu, 1995).

\section{CONCEITO}

Faz parte da natureza humana a necessidade de rotular, classificar e conceituar os termos adequadamente. Entretanto, tratando-se especificamente dos "produtos da floresta", ocorrem alguns problemas e divergências de opiniões.

Inicialmente, o termo "produtos menores da floresta" era adotado, mas este termo denota um caráter físico, de tamanho, e o seu uso não é apropriado. A variedade e volume dos produtos da floresta ultrapassam, em muito, os chamados "produtos madeireiros tradicionais", bem como o seu valor, quando corretamente avaliados, a ponto de exceder o 
valor dos produtos madeireiros.

Para alguns autores o termo "produtos não madeireiros" é insatisfatório porque pode excluir importantes recursos como combustível da madeira e madeira de pequeno diâmetro para construção. Por outro lado, pode haver má interpretação desse conceito e serem incluídos na definição outros produtos como por exemplo a polpa da madeira.

Dessa forma o termo "produtos não madeireiros da floresta" e termos similares, como: "menores", "secundários" e "nontimber" (no sentido de madeira para construção), surgiram como expressões para o vasto aparato de produtos, animais e vegetais, que não se refiram à madeira derivada das espécies arbóreas da floresta. Assim, produtos não madeireiros podem ser coletados da floresta, produzidos como plantas semi domesticadas em plantios ou em sistemas agroflorestais, ou produzidos em graus variados de domesticação. O seu "status" de selvagem ou semi domesticado os distinguem dos plantios agrícolas estabelecidos, tais como cacau, borracha ou café.

Entretanto, para Cherkasov (1988), todos os produtos que crescem e são colhidos em áreas florestais, e que não são resultantes da atividade agrícola (cereais, forragem, etc), horticultura, criação de gado, produção de peixes em açudes ou represas na floresta, deveriam representar uma categoria especial, de manejo especializado, ainda que sejam obtidos a partir de recursos não madeireiros (por exemplo, plantio de sementes).

Segundo Wickens (1991), produtos não madeireiros da floresta podem ser definidos como todo o material biológico (que não madeira roliça de uso industrial $\mathrm{e}$ derivados de madeira serrada, placas, painéis e polpa de madeira) que podem ser extraídos por exemplo, de ecossistemas naturais ou de plantios manejados, e serem utilizados para uso doméstico ou comercial, ou dotados de uma significância social, religiosa ou cultural específica.

Beer \& Modermott (1989), citados por Mok (1991), definem produtos não madeireiros como sendo todo material biológico obtido em ecossistemas florestais natural ou artificial, exceto a madeira.

A tendência atual é a aplicação do termo "produtos florestais não madeireiros", utilizado pela FAO. Finalmente, a dificuldade em determinar um conceito para os produtos não madeireiros da floresta, que seja aceito por todos, somente será resolvida quando forem desenvolvidas e aplicadas práticas e políticas de desenvolvimento ajustadas para as áreas florestais, de forma a dar a esses produtos a atenção que eles merecem. Somente assim o termo "produtos não madeireiros da floresta" pode ser apropriadamente aplicado e entendido como sendo a totalidade dos benefícios derivados dos recursos florestais (Unasylva, 1991).

\section{CLASSIFICAÇÃO E DESCRIÇÃO}

Uma bem definida classificação de produtos é a base para uma eficiente coleta de dados e informações. Entretanto, encontram-se diferentes abordagens e classificações na literatura.

Mok (1991) classifica os produtos não madeireiros, oriundos de plantas, em:

1. Comestíveis: frutas, sementes, palmitos, sagu, açúcar e especiarias;

2. Medicinais;

3. Materiais estruturais: fibras, bambus e ratam;

4. Químicos: óleos essenciais, látex, resinas, gomas, taninos e corantes; e

5. Plantas ornamentais: orquídeas, e outras.

Para Wickens (1991), os produtos não madeireiros da floresta incluem plantas usadas para:

1. Alimentos (comestíveis);

2. Forragem;

3. Combustível;

4. Medicinais;

5. Fibras;

6. Bioquímicos;

7. Animais: pássaros, répteis, peixes, insetos, etc., para a obtenção de alimentação, peles, penas, etc.

Segundo este autor, o uso do ecossistema para, a exemplo, recreação, reservas naturais, manejo de várzeas, entre outros, são considerados como serviços da floresta.

No Sudeste Asiático os produtos não madeireiros mais importantes são classificados em (Beer, 1996):

1. Alimentos: caça, pesca, nozes, 
cogumelos, especiarias, mel e ninho de pássaros;

2. Materiais estruturais: ratam e bambu;

3. Químicos: resinas, óleos essenciais, gomas, látex, tanino e corantes;

4. Ervas medicinais;

5. Forragem;

6. Combustível: lenha

Já para Cherkasov (1988), os recursos florestais deveriam ser divididos, de modo geral, em madeireiros, não madeireiros e recursos especiais. A proposta deste autor para a classificação dos produtos não madeireiros inclui os serviços da floresta, e é a seguinte:

1. Vegetais:
a) alimentos: frutos selvagens $\mathrm{e}$ cogumelos;
b) plantas medicinais;
c) plantas melíferas;
d) plantas para uso industrial;
e) forragem.

2. Vida selvagem:

a) vertebrados: caça (pássaros, animais mamíferos e peixes);

b) invertebrados.

3. Conservação ambiental e uso social
a) Conservação ambiental
- regulação climática
- regulação e conservação da água
- proteção do solo
b) Uso social:
- Saúde;
- recreação.

Desta forma, os usos não madeireiros incluem principalmente as plantas comestíveis (frutos selvagens, nozes, bagos, cogumelos), plantas usadas pelas abelhas $\mathrm{e}$ indústria (tanino, corantes, óleos voláteis), e plantas para a forragem.

A vida selvagem inclui vertebrados (principalmente pássaros, animais e peixes) e invertebrados que desempenham importante papel na vida da floresta.

Usos não produtivos podem ser subdivididos em conservação ambiental e uso social. O primeiro inclui a regulação do clima e da água, funções de preservação da água e proteção do solo florestal. O uso social inclui a saúde, recreação, defesa entre outros.

Musgo e junco são grupos especiais de recursos não madeireiros, os quais são coletados em florestas e extensamente utilizados em construções, indústria de papel, etc.

Resinas e seivas açucaradas são recursos difíceis de classificar, pois fazem parte dos recursos da madeira, são produtos das árvores, mas podem ser considerados como produtos não madeireiros. Até o presente, o sangramento da resina é considerado como um tipo independente de uso florestal, enquanto que a coleta de seiva se relaciona aos usos da floresta.

Silva (1993) identificou nove grupos de produtos não madeireiros explorados no Brasil. Estes grupos foram diferenciados da seguinte forma:

1. oleaginosas (andiroba, babaçu, copaíba, cumaru, ucuri, macaúba, olicica, pequí, tucum, ucuuba, e outros);

2. alimentícios ( açaí, castanha de cajú, castanha do Pará, erva mate, mangaba, palmito, pinhão, umbú);

3. aromáticos, medicinais tóxicos e corantes (ipecacunha, jaborandi, jatobá, quina, timbó, uruçu e outros);

4. pinheiro (nó de pinho);

5. borracha (cauchu, hevea - coagulada e líquida - e mangabeira);

6. gomas (balata, maçaranduba e sorva);

7. cera (carnaúba - cera e pó - e licurí);

8. fibras (buriti, carnaúba, caroá, cipóimbé, butiá, guaxima, malva, paina, piaçava, taboa, tucum);

9. tanantes (angico, barbatimão, mangue e outros.

De acordo com a classificação utilizada pelo IBGE na publicação denominada Produção da extração vegetal e silvicultura, o termo "produtos extrativos" da floresta, compreende:

1. borrachas: hevea e caucho;

2. Gomas não elásticas: sorva, massaranduba e balata;

3. Ceras: carnaúba;

4. Fibras: piaçava, carnaúba e buriti;

5. Tanantes: barbatimão e angico;

6. Oleaginosos: copaíba, amêndoa de cumaru, babaçu, licuri, tucum, oiticica, pequi e outros;

7. Alimentícios: mangaba, castanha de cajú, umbú (fruto), pinhão, palmito, castanha do Pará, erva-mate cancheada, açaí (fruto);

8. Aromáticos: raíz poaia, folha de jaborandi 
e semente de urucum; e

9. Sub-produtos da silvicultura: resina, folha de Eucalyptus, casca da Acácia negra e nó de pinho.

\section{METODOLOGIA DE VALORAÇÃO}

A importância de se desenvolverem metodologias para a valoração dos produtos não madeireiros decorre da necessidade de serem conhecidos não apenas os valores dos produtos em si, para efeito de comercialização, mas também para se obter o valor do recurso florestal como um todo, e o seu valor de substituição.

Há diversas maneiras de atribuir valor aos recursos naturais (florestas e outros ecossistemas). Uma delas seria através da capitalização do valor atribuído às informações extraídas desses recursos. Neste caso, a análise custo-benefício envolvida em substituir uma floresta nativa por um sistema artificial deveria incluir, por exemplo, o custo de oportunidade da floresta, ou seja, o valor capitalizado de produtos potencialmente desenvolvidos no longo prazo, com base no registro do meio século anterior (Anderson, 1994).

Segundo este autor, nem o recurso biológico de informações contido em florestas tropicais e outros ecossistemas, nem o fluxo de aplicações desenvolvidas pelas populações tradicionais são valorizados pelos mercados atuais. Como o valor dos serviços de conservação e o valor da pesquisa das populações tradicionais não são remunerados, surge a ilusão perniciosa de que a manutenção de fundos de florestas em pé é antieconômica, e de que a atividade das populações tradicionais é irracional.

Segundo May (1991), vários estudos recentes sugerem que o valor dos produtos extraídos sustentavelmente de uma área florestal particular poderia, muitas vezes, exceder o ganho obtido se a terra fosse convertida em pastagem ou área agrícola.

Portanto, é preciso qualificar as alternativas comumente apresentadas como mais eficientes, descontando do produto bruto anual a perda do patrimônio de recursos; e valorizar os usos predominantemente extrativistas da floresta, adicionando a eles os serviços de conservação de patrimônio e de pesquisa e desenvolvimento.
É importante destacar aqui o que vem a ser valor econômico relacionado ao ambiente natural, e distinguir entre valor de uso e valor intrínseco. O valor de uso resulta do uso que se faz do ambiente, como por exemplo, a extração de produtos madeireiros e os serviços ambientais (regulação climática, biodiversidade, etc), incluindo, portanto, os valores diretos e indiretos do ambiente. Já o valor intrínseco compreende os valores de bens que não possuem interesse de uso pelos seres humanos, ou seja, o seu valor de existência.

Entretanto, existem algumas divergências entre autores acerca destas conceituações e classificações. Kopp \& Smith (1993), citados por Merico (1996), ressaltam que, se o valor econômico total excede seu valor de uso, a diferença pode assumir uma variedade de termos como "valor de preservação", "valor intrínseco", "valor de existência", e ainda "valor de não-uso".

Segundo Motta in Tauk (1991), na literatura econômica distinguem-se três diferentes valores que compõem o valor do ambiente de acordo com a seguinte expressão: valor total do ambiente $=$ valor de uso + valor de opção + valor de existência.

Dessa forma, os principais métodos de valoração econômica apresentados a seguir tem por objetivo a determinação do valor de uso da floresta, ou seja, seus bens e serviços.

\section{Principais métodos de valoração}

De modo geral, os métodos de valoração não possuem uma classificação rígida, podendo-se utilizar diversos enfoques na aplicação dos mesmos, dependendo dos propósitos. No entanto, do ponto de vista didático, torna-se interessante uma abordagem maleável desses métodos que permita as alterações que se fizerem necessárias durante suas aplicações. Assim, os métodos de valoração ambiental podem ser divididos em diretos e indiretos.

\section{Métodos Diretos}

Relacionam-se diretamente aos preços de mercado ou à produtividade. São possíveis de se aplicar quando uma mudança na qualidade ambiental ou na quantidade de recursos naturais afeta a produção ou capacidade produtiva do processo econômico (Merico, 1996). 
São exemplos de métodos diretos de valoração ambiental: preço líquido, mudanças na produtividade, custo de oportunidade, custo de doenças, custo de reposição, entre outros.

Segundo Chopra (1993), os principais métodos, ou abordagens, utilizados para estimar o valor dos bens e serviços produzidos pela floresta são:

Mudança na produtividade: quando um produto possui mais de um uso, seja intermediário ou final, o valor do produto para um dos usos pode ser considerado pela perda de produtividade com o outro uso. Assim, o valor do combustível da madeira pode ser projetado pela perda do produto marginal na agricultura, por causa da utilização do combustível como esterco.

Alternativa tecnológica: se alternativas tecnológicas para produzir o mesmo bem ou serviço são viáveis, o custo de obter certo bem ou serviço utilizando uma determinada tecnologia é a medida do valor de uso dos recursos requeridos para produzir este mesmo bem através de outra alternativa. Assim, se um projeto de reflorestamento resulta em conservação do solo, o valor desta pode ser mensurada pelo custo dos nutrientes necessários à restauração da produtividade do sítio, e do custo de dragar rio abaixo para evitar os efeitos da erosão.

Custo de oportunidade da mão-deobra: se a mão-de-obra é o maior input requerido para o aumento do bem ou serviço, o seu custo de oportunidade pode ser tratado como uma aproximação do valor do produto. A regeneração natural de produtos florestais $\mathrm{e}$ a forragem encontram-se nesta categoria.

Dados experimentais: dados experimentais podem algumas vezes fornecer uma estimativa do valor de alguns tipos de funções ambientais. Por exemplo, valores experimentais dos nutrientes reciclados através do litter que cai nos diferentes tipos de florestas, podem dar uma estimativa de um tipo de função ambiental fornecida pela floresta.

Dados secundários: contas nacionais proporcionam dados de despesas decorrentes em diferentes tipos de serviços e podem ser usados para obter o valor de mercado de serviços, como o turismo e a recreação.

De acordo com Godoy et al (1993), a determinação do valor líquido dos produtos não madeireiros de uma floresta, quando a extração é sustentada, pode ser obtida através de:

$$
\sum_{\mathrm{i}=0}^{\mathrm{n}} \mathrm{Q}_{\mathrm{i}}\left(\mathrm{P}_{\mathrm{i}}-\mathrm{C}_{\mathrm{i}}\right)
$$

onde,

$\mathrm{Q}_{\mathrm{i}}=$ quantidade de bens extraídos

$\mathrm{P}_{\mathrm{i}}=$ preço do bem (deve ser equivalente ao preço em um mercado competitivo, sem nenhuma externalidade)

$\mathrm{C}_{\mathrm{i}}=$ custo da extração

$\mathrm{i}$ = produto não madeireiro

Entretanto, se a exploração não for sustentada, ajustes devem ser feitos de modo que a eventual depredação dos produtos seja adicionada aos custos, baseada nos dados esperados da extração.

Os autores deixam bem claro que, apesar de todas as correções, esse método de valoração subestima o valor dos produtos não madeireiros de uma floresta, porque não captura integralmente os benefícios dos serviços.

A quantificação dos produtos extraídos, através de inventários, e a determinação dos custos, não causam grandes problemas. A dificuldade maior ocorre na determinação do valor monetário ou preço do produto.

Neste sentido, Godoy et al (1993), citam os seguintes métodos para a obtenção dos preços dos produtos não madeireiros:

- Fazer uso dos preços existentes ou que prevalecem em mercados existentes. Por exemplo, produtos não madeireiros podem a princípio não ter mercado, mas podem ser trocados por outros que tenham. Neste caso é fácil atribuir um preço para o produto em que se está interessado;

- Usar o valor de um produto próximo que possua preço. Isto requer o estabelecimento de um preço relativo, entre os produtos com e sem preço, que pode ser efetuado com base nas características dos produtos;

Entretanto, se nenhum dos métodos acima for possível de ser utilizado, o preço pode ser obtido através da Abordagem da Valoração do Contingente, que faz parte dos métodos indiretos de valoração. Neste caso, os usuários do produto são questionados quanto à sua disposição à pagar (DAP) pelo mesmo.

A determinação da quantidade (Q) 
pode ser feita através de: inventário (estoque quantitativo na floresta) ou do fluxo (quantidade atualmente utilizada pelas pessoas). Alguns pesquisadores valorizam o inventário, outros o fluxo, e outros ainda utilizam os dois. Entretanto, a diferença entre o inventário e o fluxo pode ser grande.

Segundo Godoy et alli (1993) complementam, afirmando que o método mais adequado é identificar, contar, pesar e medir os produtos assim que estes entram nos locais (aldeias ou vilarejos) a cada dia. Essa técnica pode ser dificultada se os extratores estiverem dispersos em diferentes aldeias, se consumirem os bens na floresta, ou se eles extraírem bens à noite ou antes do amanhecer.

Já a determinação do custo da extração (C) deve incluir o custo dos materiais usados, o tempo de trabalho diretamente associado com a procura, extração, processamento, e transporte dos bens da floresta até os vilarejos ou mercado, e o custo temporal dos recursos, ou seja, o benefício perdido pela demora ou atraso na venda ou uso do bem (Godoy et al, 1993).

Pesquisadores podem entrevistar extratores ao final do dia, para decidir como o tempo é despendido na floresta.

\section{Métodos indiretos}

São utilizados quando os benefícios ambientais não são possíveis de serem valorados, mesmo que indiretamente, pelo comportamento do mercado. Nesse caso, simula-se o mercado através de julgamentos de pessoas, ou seja, os métodos estão baseados em avaliações subjetivas a respeito do comportamento do mercado, ou pela construção de mercados hipotéticos.

Utilizam-se, principalmente os métodos de valoração contingente, custos de viagem e avaliação hedônica (Benakouche \& Cruz, 1994; Merico, 1996).

Os métodos do custo de viagem e avaliação hedônica estimam valores com base em comportamento observado ou observações de mercado.

De acordo Merico, (1996), em alguns casos, quando mercados para bens e serviços ambientais não existem, ou não existem mercados alternativos para se proporem substituições, há a necessidade de se aplicarem métodos de valoração contingente, ou seja, com certo grau de incerteza. A através da valoração contingente estimam-se valores com base em afirmações do indivíduo a respeito de preferências ou escolhas que fariam entre alternativas apresentadas numa pesquisa, ou seja, a partir das preferências dos consumidores e não das observações de mercado. Pode-se aplicar esses métodos para elementos da natureza, tal como a biodiversidade, patrimônio paisagístico, áreas de lazer, ou qualquer outra situação na qual não existam valores de mercado.

Em geral, a análise econômica do desenvolvimento florestal se depara com dois problemas. Primeiro, muitos dos benefícios das florestas são de difícil valoração. E, segundo, os benefícios freqüentemente ocorrem alguns anos após os custos. Isso, aliado ao fato dos custos serem mais facilmente estimados que os benefícios, significa que a floresta normalmente mostra um baixo retorno.

A valoração dos produtos não madeireiros da floresta também é bastante dificultada pelas medições inadequadas dos custos, quantidades extraídas e preços. Apesar dos pesquisadores estarem produzindo importantes estudos de caso, os resultados destes não podem ser diretamente comparados devido aos diferentes métodos que tem sido utilizados. É preciso maior atenção aos problemas de metodologia se futuros estudos de valoração pretendem produzir resultados generalizáveis (Godoy et al,1993).

Segundo esse autor, não existe substituto para a observação direta por vários anos. O melhor método para estudos de valoração econômica irá depender da base cultural das pessoas estudadas e acordos estabelecidos entre as partes. Os recursos financeiros e o tempo disponível também influenciam na escolha do método.

\section{O mercado de produtos não madeireiros}

Um caminho para agregar valores para o manejo sustentado de florestas é a identificação de uma cadeia marginal de produtos com valor comercial na floresta e então pela demonstração à comunidade das enormes possibilidades de uso dos recursos naturais através de técnicas aprimoradas de mercado. Isto é de fundamental importância para o estabelecimento de políticas de mercado baseado nas oportunidades oferecidas por produtos que não madeira para permitir 
harmonia entre o desenvolvimento e a conservação dos recursos (Lintu, 1995).

Os produtos não madeireiros representam hoje um dos grupos mais desafiadores do ponto de vista mercadológico, graças a seu número, versatilidade, variedade de usos e diferenciação de outros produtos básicos. Anderson (1992) afirma que, os produtores poderiam ter ganhos pessoais, incluindo pequenos agricultores e agricultura de subsistência, ou plantadores de larga-escala de produtos industrias se passassem a fornecer bens e matéria prima para o posterior processamento pela indústria. $\mathrm{O}$ mesmo autor cita que o mercado de produtos florestais é um bom nicho de mercado tanto para países desenvolvidos como para aqueles ainda em desenvolvimento.

\section{As principais características do mercado de não madeireiros são:}

\section{$\underline{\text { Práticas de mercado }}$}

Segundo Lintu (1995), as descrições disponíveis de práticas de mercado são muito limitadas para retratar as atividades como as formas de beneficiamento, empacotamento, seleção de material, entre outras. Descrições de práticas de mercado são raras, a despeito do fato dos consumidores estarem, ultimamente, muito mais dispostos a adquirir produtos advindos de atividades mais naturais.

O mercado de produtos não madeireiros que é usado como matéria prima para a indústria é normalmente qualificado em duas categorias principais: o mercado da matéria bruta, não beneficiada e o mercado dos produtos semi manufaturados, tanto para o consumidor final como o fornecimento para a utilização em outras indústrias.

\section{Informações de mercado}

Para Lintu (1995) o marketing é baseado num amplo sistema de informações. Um marketing eficiente requer informações com qualidade e quantidade regularmente, continuamente e com o menor custo possível. São necessárias informações de mercado (oferta e demanda), que descrevam fatores de mercado, competitividade, marketing ambiental e instituições envolvidas no processo.

Sistematicamente coletadas, analisadas e disseminadas as informações são essenciais. Grande parte dessas informações são coletadas em pesquisas de diferentes níveis. Entretanto essas informações nem sempre são facilmente usadas. Uma atenção crescente deve ser dada para a coleta de informações de mercado, no uso pela indústria ou pelo consumidor final. Paralelamente, a coleta de informações e fatores de mercado precisa ser aprimorada.

Uma correta classificação de produtos e uma eficiente forma de coleta de dados são essenciais. A FAO deu um primeiro passo na classificação e sistema de definição, apresentando para discussão uma tentativa de classificação de mercado.

A demanda de alguns produtos não madeireiros, é derivada da atitude do consumidor final. Para melhor entender as atuais necessidades do mercado consumidor, valores específicos que o consumidor associa com os produtos devem ser largamente difundidos.

Parte dos estudos relacionados ao mercado primário e de processamento de produtos deve ser conduzido para mercados não só interno mas principalmente externo. Mas, devido aos altos custos para o desenvolvimento de pesquisas de mercado externo, para conduzir este processo é necessário a associação dos produtores em cooperativas agrícolas, associação de indústrias e outros arranjos institucionais. Em alguma instância, organizações internacionais podem assistir no planejamento e financiamento dos estudos.

\section{Capacidade de mercado}

Entende-se por capacidade de mercado um conhecimento básico do mercado, experiência para colocar o conhecimento em prática e atitudes corretas para reconhecer e apreciar os valores de mercado como uma das funções básicas no negócio de produtos não madeireiros. A capacidade de mercado é necessária em todos os níveis, desde o produtor de matéria prima até o industrial. Membros do mercado e dos canais de distribuição que estão especificamente envolvidos no processo devem ter esta capacidade para suas atividades do dia-a-dia. Órgãos oficiais do governo em todos os níveis de decisão, bem como as autoridades envolvidas com fiscalização, necessitam ter 
uma compreensão básica do mercado. Existem diversas pessoas em vários níveis de governo e na iniciativa privada, envolvidas na promoção e difusão dos produtos não madeireiros que carecem de um conhecimento mínimo das capacidades de mercado (Lintu 1995).

Hoje existe uma grande carência de informações no que se refere ao mercado de produtos não madeireiros. Alguma difusão de informação e oferta de cursos relacionados a produtos não madeireiros têm sido oferecidos aos países em desenvolvimento, mas não por iniciativas governamentais. Esforços em diversos âmbitos através de ONGs e outras fundações tem sido realizados com o objetivo de oferecer treinamentos aos interessados em trabalhar com produtos não madeireiros, em função de um manejo sustentado.

Relevantes materiais para treinamento têm sido produzidos pela FAO e pelo ITC (International Trade Center), e por outras organizações, para seminários e workshops de marketing de produtos não madeireiros.

\section{Suporte institucional}

Wickens (1991) descreve que o apoio institucional para o mercado é providenciado basicamente em dois níveis. Num nível superior é formado pelas políticas governamentais e pela implementação de sistemas de regulação do governo. Em nível operacional, o suporte institucional compreende os vários arranjos de cooperativas de produtores, serviços florestais, organizações de padronização de produtos, monitoramento de qualidade e desenvolvimento de pesquisas. Outro fator importante é o financiamento e abertura de créditos para os produtores e comerciantes de produtos não madeireiros.

O trabalho de várias entidades públicas e privadas contribuem ambas no incremento das oportunidades oferecidas pelo mercado de produtos não madeireiros, em concordância com o uso sustentável e desenvolvimento racional dos recursos florestais.

O mercado de produtos florestais é ainda recente $\mathrm{e}$ tem muito que ser desenvolvido e explorado. Hoje, o mercado se apresenta de forma bastante instável, concentrando-se hora em alguns produtos, hora em outros.

Isto se deve basicamente a falta de política de mercado desses produtos. Essa falta tem levado o mercado a oscilar de acordo com a simples e total vontade do consumidor final. Sem uma estratégia fixa, bem determinada e com a falta de informações disponíveis para o aprimoramento do processo, o mercado hoje está sujeito a não crescer em volume e a ficar num nível pequeno. Com o advento da globalização e a ampliação de mercados há uma grande possibilidade/probabilidade que ocorra o desaparecimento deste nicho tão valioso para o desenvolvimento sustentado das florestas tropicais.

\section{CONCLUSÕES}

- Apesar da conceituação e da classificação dos produtos não madeireiros estarem em contínua discussão e seguirem diferentes tendências, no Brasil o IBGE vem adotando uma classificação em grupos de produtos extrativos, desconsiderando outras abordagens mais biológicas, de serviços da floresta, ou ainda de conservação ambiental.

- A análise de mercado e as técnicas de valoração de produtos não madeireiros são pouco disseminadas no Brasil. Porém, seria importante a realização de estudos que aprofundassem as questões de mercado e de valoração desses produtos devido a diversidade e extensão do ecossistema florestal no território brasileiro.

- Este panorama de conceitos, classificação, valoração e descrição de mercados de produtos não madeireiros vem de encontro com a necessidade urgente de um maior detalhamento da importância sócio-econômica desse grupo de produtos, contribuindo para uma nova linha de pesquisa florestal.

\section{REFERÊNCIAS}

ANDERSON, A. B. 1994. Extrativismo vegetal e reservas extrativistas: limitações e oportunidades. In: O destino da floresta reservas extrativistas e desenvolvimento sustentável na Amazônia. Rio de Janeiro: Relume- Dumara, 276 p.

BEER, J. H. 1996. Subsistence use and market value of non-timber forest products: the example from southeast Asia: In: Netherlands Commitee for IUCN. 9-11.

BENAKOUCHE, R. \& CRUZ, R. S. 1994. 
Avaliação monetária do meio ambiente. São Paulo: Makron Books, 198 p.

CAMPBELL, J. Y. \& TEWARI, D. D., 1996. Increased development of non-timber forest products in India: some issues and concerns. In: Unasylva, 47(187): 26-31.

CHERKASOV, A. 1988. Classification of non-timber resources in the USSR. In: Acta Bot. Fennica, 136: 3-5. Helsinki:

CHOPRA, K., 1993. The value of non-timber forest products: an estimation for tropical deciduous forest in India. In: Economic Botany, 47(3): 251-257. New York: Botanical Garden, Bronx. N.Y.
IBGE. 1986. Produção da extração vegetal e Silvicultura.

LINTU, L. 1995. Marketing non-wood forest products in developing countries. In: Unasylva, 46(183): 37-41.

MAY, P. 1991. Building institutions and markets for non-wood forest products from Brazilian Amazon. In: Unasylva, 42(165): 916.

MENDELSON, R. O. et allii, 1996. The economic value of managing the açaí palm (Euterpe oleracea Mart.) in the floodplains of the Amazon estuary, Pará: Brazil. In: Forest Ecology and Management, 87: 163-173.

MERICO, L. F. K. 1996. Introdução à economia ecológica. Blumenau: FURB, p. 83101.

MOK, S. T., 1991. Production and promotion of non-wood forest products. In: $10^{\circ}$ CONGRÈS FORESTIER MONDIAL, Revue Forestière Française, Hors série $n^{\circ} 6$. Anais... Paris: p. 103-111.

SILVA, JOSÉ DE A. Análise qualiquantitativa da extração e do manejo dos recursos florestais da Amazônia brasileira: uma abordagem geral e localizada ( Floresta Estadual do Antimari - AC). Tese de doutorado. UFPR- Curitiba: 1996.

TAUK, S. M. 1991. As técnicas das análises de custo-benefício na avaliação ambiental. In: Análise ambiental: uma visão multidisciplinar. São Paulo: FAPESP, p. 126130.

UNASYLVA, 1991. Learning to see the forest through the trees. In: Unasylva, 42(165): 2.

WICKENS, G. E. 1991. Management issues for development of non-timber forest products. In: Unasylva, 42(165): 3-8. 